Abbreviated Key Title: Sch J Econ Bus Manag

ISSN 2348-8875 (Print) | ISSN 2348-5302 (Online)

Journal homepage: https://saspublishers.com/sjebm/

\title{
Research on Supply Chain Model Based on Guaranteed Financing
}

Bian Ying-Jin"

School of Management, Shanghai University, Shangda Avenue, Baoshan District, Shanghai, China

DOI: $10.36347 /$ sjebm.2020.v07i02.003

| Received: 12.02.2020 | Accepted: 20.02.2020 | Published: 25.02.2020

*Corresponding author: Bian Ying-Jin

Abstract

Review Article

When small and medium-sized enterprises face financial constraints, they often encounter financing difficulties and expensive financing problems. This not only seriously affects the performance of enterprises, but also reduces the synergy efficiency of the entire supply chain. This paper considers the three-tier supply chain model of retailers facing the problem of capital constraints, designs a credit guarantee financing contract for retailers, and enables retailers to obtain certain loans from banks, so as to solve their financing problems. This paper considers the retailer's initial capital, as well as the residual value of unsold goods, and so on, and studies how retailers make optimal order decisions in the face of initial shortage of funds.

Keywords: Guaranteed financing; Capital constraints; Supply chain model; Loan decision.

Copyright @ 2020: This is an open-access article distributed under the terms of the Creative Commons Attribution license which permits unrestricted use, distribution, and reproduction in any medium for non-commercial use (NonCommercial, or CC-BY-NC) provided the original author and source are credited.

\section{INTRODUCTION}

As we all know, the survival and development of small and medium-sized enterprises play a vital role in promoting the development and vitality of our national economy. According to the statistics of the National Bureau of Statistics at the end of 2018, the total number of small and medium-sized enterprises reached369,000, of which the number of individual industrial and commercial households exceeded 70 million. Small and medium-sized enterprises contribute more than $50 \%$ of the country's tax revenue, more than $60 \%$ of GDP, more than $70 \%$ of technological innovation and more than $80 \%$ of the national jobs [13].

However, reality is far from the contribution of Small and Medium-sized enterprises, considering that it faces survival problems of its own. Because of the small and medium-sized enterprises' thin strength, incomplete information and lack of collateral, their financing channels are very narrow, it is difficult to finance through traditional banks. However, supply chain finance has opened up another financing channel for small and medium-sized enterprises $[4,5]$.

A supply chain is a network structure that provides products or services to end customers through upstream and downstream companies, such as raw material suppliers, distributors, and retailers. Whether this network structure can achieve system optimization usually depends on the ability of the core enterprise to influence the coordination and control of the whole supply chain. Supply chain finance, in short, is a financing model in which banks link core and upstream and downstream firms to provide flexible financial products and services [6].

Theoretically, after the theory of supply chain finance is put forward and applied abroad, the domestic gradually develops from practical application to theoretical research and analysis. Based on this, most domestic scholars study supply chain finance from the development model of supply chain finance business financing. Then, the risk assessment and control of supply chain finance have attracted the attention of many scholars at the same time. In decision-making and coordination, most scholars study wholesale supply contracts based on secondary supply chains, repurchase contracts, kickback contracts, and decision-making and coordination between supply chain retailers and suppliers. Only a few scholars in China have considered the impact of capital constraints on strategies when studying supply chain decision-making. In the case of banks joining the supply chain, it is rare to study the decision-making and coordination of supplier-retailerbanks under the relevant contract, and less research on the tripartite strategy in the supply chain under the supplier guarantee contract $[7,8]$.

Therefore, considering that supply chain financing is actually the business model characteristics of many small and medium-sized enterprises, combined with the actual situation, this paper discusses the 
situation of retailers ordering suppliers as the core enterprises upstream in the supply chain. In the model of single supplier, single retailer, and bank, the core enterprise provides the retailer with conditional financing guarantee and discusses the financing decision of the supplier's credit guarantee when the retailer is faced with the financial constraint [9-11].

\section{SUPPLY CHAIN MODEL BASED ON GUARANTEED FINANCING \\ Description of the problem and basic assumptions}

Common supply chains contain a supplier and a retailer and a financial institution, which generally refers to a bank. Retailers face the problem of seeking the best order. Suppliers, as core businesses, provide guarantees to retailers [12].

Before the start of the sales season, the retailer has a financial constraint, its own capital is $L$, the retailer orders at wholesale prices, orders unit goods, and sells goods at unit prices, $p>w$.

Suppliers, as core businesses, need to guarantee the retailer's borrowing to the bank. The wholesale price offered by the supplier is $w$, the production cost is $C$, and the retailer cannot fully sell all orders after the recovered residual value is $v$, exists $w \geq c \geq v$. The supplier provides the retailer with a guarantee of the loan, the ratio of which is $\lambda(0<\lambda<1)$.

For banks, borrowing rates are key to their revenues. Assuming that the risk-free interest rate of a bank is $r_{f}$, the risk-free rate is based on the base rate of deposit, and the loan interest rate $r$ in practice is higher than the risk-free rate. That is, $r>r_{f}$. Since banks' lending decisions are often relevant to the overall market environment, in this article banks do not participate in the supplier-retailer game.

The demand of the market is changed randomly according to the market environment, and the market demand is $D$, which obeys the negative index distribution. The distribution function $F\left({ }^{*}\right)$ is continuous, and the probability density function meets $f()^{\circ}>0$, which is the case.

And we make the assumption that all participants will not have ethical issues throughout the operation of the supply chain, so the ethical risk is 0 . Logistics and other participation in all aspects, does not affect the transportation and warehousing of products, the supply chain for retailers to fully understand the business, with the feasibility of supply chain financing guarantee.

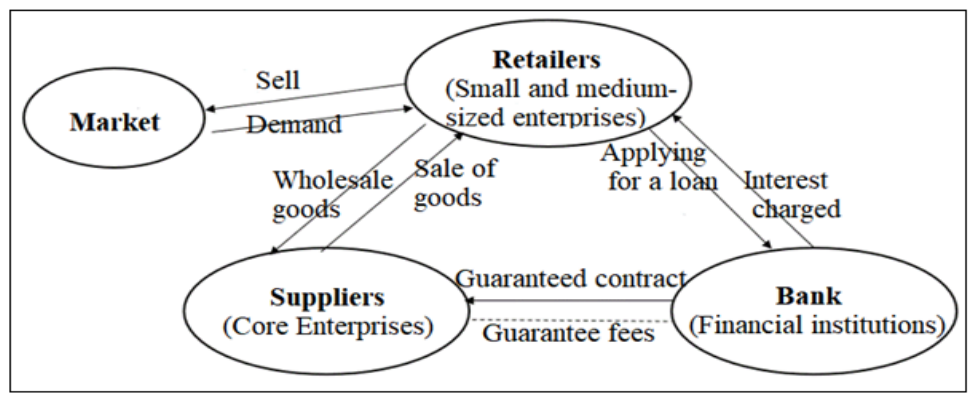

Fig-1: Supply Chain Credit Guarantee Model Figure

\section{Symbol Description}

Table-1: Mathematical symbols in the model

\begin{tabular}{|c|c|c|}
\hline Symbol & Significance & Scope of application \\
\hline$w$ & Wholesale price of a single item & $w \geq c$ \\
\hline$p$ & Single sale price & $p \geq w$ \\
\hline c & Cost of a single item & $c \geq v$ \\
\hline$v$ & Single-item recovery residual value & $v>0$ \\
\hline$Q$ & Orders & \\
\hline$D$ & Market demand & Obedience to negative exponential distribution $F\left({ }^{*}\right)$ \\
\hline$L$ & Retailers own their own money & \\
\hline$\lambda$ & Supplier guarantee ratio & $0<\lambda<1$ \\
\hline$r$ & Bank loan rates & $r>r_{f}$ \\
\hline$r_{f}$ & Bank Security Rate & Based on deposit rate \\
\hline
\end{tabular}




\section{SUPPLY CHAIN DECISIONS}

At the beginning of the sale, the retailer orders a piece of $Q$ item from the supplier and orders it according to the needs of the market. The wholesale price of goods is $w$. Retailers determine the need for a bank loan based on their own capital $L$ and wholesale prices $w$.

For retailers, the volume of goods ordered is the key to determining their earnings, but due to the limitations of their own funds, they cannot determine a sufficient amount of goods as they wish, so there are two scenarios in which they borrow from banks.

\section{Retailer Financing Decision} satisfied:

When wQ $\leq \mathrm{L}$ is met, that is, when $\mathrm{Q} \leq \mathrm{L} / \mathrm{w}$ is

At this point, the retailer's own funds are sufficient to pay for the required order and do not need to be loaned to the bank. Therefore, the bank's earnings are not taken into account, or can be understood as zero.

Assuming that the retailer's revenue is $g(Q)$, then:

$$
g(Q)=p \cdot E[\min (Q, D)]+v \cdot\{Q-E[\min (Q, D)]\}
$$

Where $E[\min (Q, D)]_{\text {is based on the mean of a small value between market demand }} D$ (random) and the retailer's order volume $Q$. $v$ is the residual value of commodity recovery.

The retailer's profit is:

$$
\pi_{r}^{1}(Q)=g(Q)-w Q=p \cdot E[\min (Q, D)]+v \cdot\{Q-E[\min (Q, D)]\}-w Q
$$

After finishing, you get:

$$
\pi_{r}^{1}(Q)=(p-v) \cdot E[\min (Q, D)]-(w-v) Q
$$

Where the market demand $D$ is subject to negative exponential distribution:

$$
F(x)=1-e^{-\sigma x}
$$

$F(x)$ is the distribution function of demand $D, f(x)$ is the probability density function:

$$
f(x)=F^{\prime}(x)=e^{-\sigma x}
$$

And $f(x)>0$ is satisfied.

Second-order guidance is carried out on the retailer's profit function. Because a second derivative of $\pi_{r}^{1}$ is less than zero, it is a convex function, so when the first derivative of $\pi_{r}^{1}$ is equal to zero, it takes the maximum value of $\pi_{r}^{1}$.

So assuming that the first derivative of $\pi_{r}^{1}$ is equal to zero, you can get:

Therefore,

$$
\begin{gathered}
\qquad Q_{1}=F^{-1}\left(\frac{p-w}{p-v}\right) \\
Q^{*}(\lambda, r)=Q_{1}=F^{-1}\left(\frac{p-w}{p-v}\right) \text { is met, get } \max _{Q} \pi_{r}^{1}(Q) .
\end{gathered}
$$

\section{Retailer Non-Financing Decision}

When $w Q \geq L$ is met, that is, when $Q \geq L / w$ is satisfied:

That is, when the retailer's own funds are insufficient to order the required quantity of goods, the reforest needs to apply to the bank for a loan. Banks will determine the appropriate loan rates based on the retailer's own funds and the proportion guaranteed by the supplier, and the supplier will choose the appropriate guarantee ratio. The mathematical model for the specifics is as follows. 
The retailer's profit can be expressed as:

$$
\pi_{r}^{2}(Q)=g(Q)-w Q-r \cdot(w Q-L)
$$

Where $r$ is the bank's loan rate.

After finishing:

$$
\pi_{r}^{2}(Q)=(p-v) \cdot\left[\int_{0}^{Q} x f(x) d x+\int_{Q}^{+\infty} Q f(x) d x\right]-(w-v+r w) Q+r L
$$

Retailers are required to meet the following conditions due to the amount of credit provided by the bank:

$$
(1-\lambda) w Q \leq L
$$

So,

$$
L / w \leq Q \leq \frac{L}{w} \cdot \frac{1}{1-\lambda}
$$

First-order and second-order guidance on the retailer's profit function, sorted out:

$$
\begin{gathered}
\frac{d \pi_{r}^{2}}{d Q}=(p-v) \cdot[1-F(Q)]-(w-v+r w) \\
\frac{d^{2} \pi_{r}^{2}}{d Q^{2}}=-(p-v) \cdot f(Q)<0
\end{gathered}
$$

Because the second-order derivative of $\pi_{r}^{2}$ is less than zero, it is a convex function. So when the first derivative of $\pi_{r}^{2}$ is equal to zero, the maximum value of $\pi_{r}^{2}$ is taken.

Therefore,

$$
\frac{d \pi_{r}^{2}}{d Q}=0
$$

You can get,

$$
F(Q)=\frac{p-w-r w}{p-v}
$$

That is:

$$
Q_{2}=F^{-1}\left(\frac{p-w-r w}{p-v}\right)
$$

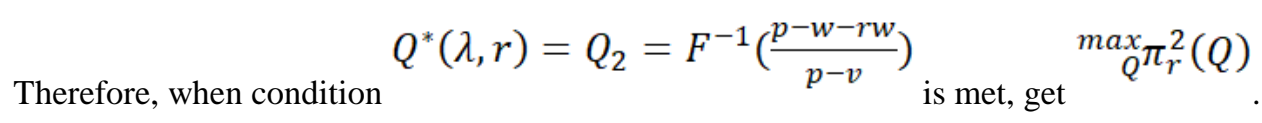

\section{Supplier Decisions}

After the best $Q^{*}$ value is known, the supplier's profit is solved:

When $Q^{*}(\lambda, r) \leq L / w$, that is, when the retailer makes a financing decision, the vendor's profit function is:

$$
\pi_{s}^{1}=(w-c) \cdot Q_{1}
$$


That is:

$$
\pi_{s}^{1}=(w-c) \cdot F^{-1}\left(\frac{p-w}{p-v}\right)
$$

When $Q^{*}(\lambda, r)>L / w$, i.e. the retailer makes anon-financing decision, the vendor's profit function is:

$$
\begin{gathered}
\pi_{s}^{2}(\lambda)=(w-c) \cdot Q^{*}(\lambda, r) \\
+\left\{g\left[Q^{*}(\lambda, r)\right]-w Q^{*}(\lambda, r)-r\left(w Q^{*}(\lambda, r)-L\right)+L\right\}
\end{gathered}
$$

Suppose this is the case:

$$
A=g\left[Q^{*}(\lambda, r)\right]-w Q^{*}(\lambda, r)-r\left(w Q^{*}(\lambda, r)-L\right)+L
$$

Here: $A$ Take a negative value, i.e. when the retailer's income is able to pay the purchase point and loan interest, the supplier is not required to bear the

$$
\begin{cases}A>0, & A=0 \\ A<0, & A=A\end{cases}
$$

guarantee fee, and if the retailer's income is less than the sum of the purchase price and interest, the supplier is required to pay some or all of the guarantee fee, i.e.:

Therefore, combined with the above calculation, you can get the supplier's profit function as follows:

$$
\pi_{s}^{2}(\lambda)= \begin{cases}(w-c) \cdot Q^{*}(\lambda, r), & A>0 \\ (w-c) \cdot Q^{*}(\lambda, r)+A, & A<0\end{cases}
$$

This section mainly describes the ordering decision in the supply chain under the constraint of funds. Based on the traditional Newsvendor Model, the relevant variables such as retailers, suppliers and banks are modeled and analyzed. A model of whether a retailer borrows from a financial institution, solves its optimal order $Q^{*}$, and establishes a supplier's revenue model, discusses the situation of the supplier's earnings in the two modes of the retailer.

\section{NUMERICAL STUDY}

As can be seen from the previous section, the retailer's earnings are affected by the amount ordered, so choosing the optimal order volume $Q^{*}$ is the key to determining revenue. Therefore, according to the mathematical model in the previous section, set the basic parameters in the study. Assuming that the market retail price is $p=15$, the wholesale price of goods is $w=10$, production cost $c=8$, residual value is $v=7$, the retailer's initial own capital is $L=50$, the market demand $D$ obeys the negative index distribution, its mean is $E(D)=\frac{1}{\sigma}$. Suppose $\frac{1}{\sigma}=7$, the bank's secure loan interest rate is $r_{f}=0.03$, the bank's loan rate $r=8 \%$, and the decision variable order amount $Q$ and supplier guarantee ratio $\lambda$.

\section{Hypothesis 1, the price of the goods sold by the retailer:}

$$
p \epsilon[10,20]
$$

Solve the impact of supplier revenue on retailers, within a reasonable pricing range. The results are shown in the table below: 
Table-2: Retailer's Optimal Guarantee Ratio and Optimal Order at Different Retail Prices

\begin{tabular}{ccccc}
\hline$p$ & $\lambda$ & $Q$ & $\pi_{r}$ & $\pi_{s}$ \\
\hline 10 & -- & 0.00 & 0.00 & 0.00 \\
11 & -- & 2.01 & 0.96 & 4.03 \\
12 & -- & 3.58 & 3.27 & 7.15 \\
13 & -- & 4.85 & 6.44 & 9.70 \\
14 & -- & 5.00 & 10.01 & 10.00 \\
15 & $5 \%$ & 5.21 & 13.60 & 10.42 \\
16 & $17 \%$ & 6.02 & 17.46 & 12.05 \\
17 & $26 \%$ & 6.76 & 21.66 & 13.51 \\
18 & $33 \%$ & 7.44 & 26.13 & 14.88 \\
19 & $37 \%$ & 7.94 & 30.81 & 15.87 \\
20 & $42 \%$ & 8.61 & 35.68 & 17.22 \\
\hline
\end{tabular}

Replace the data in the table and solve the retailer's earnings $\pi_{1}^{r}$ and $\pi_{2}^{s}$. The results are shown in the following figure:

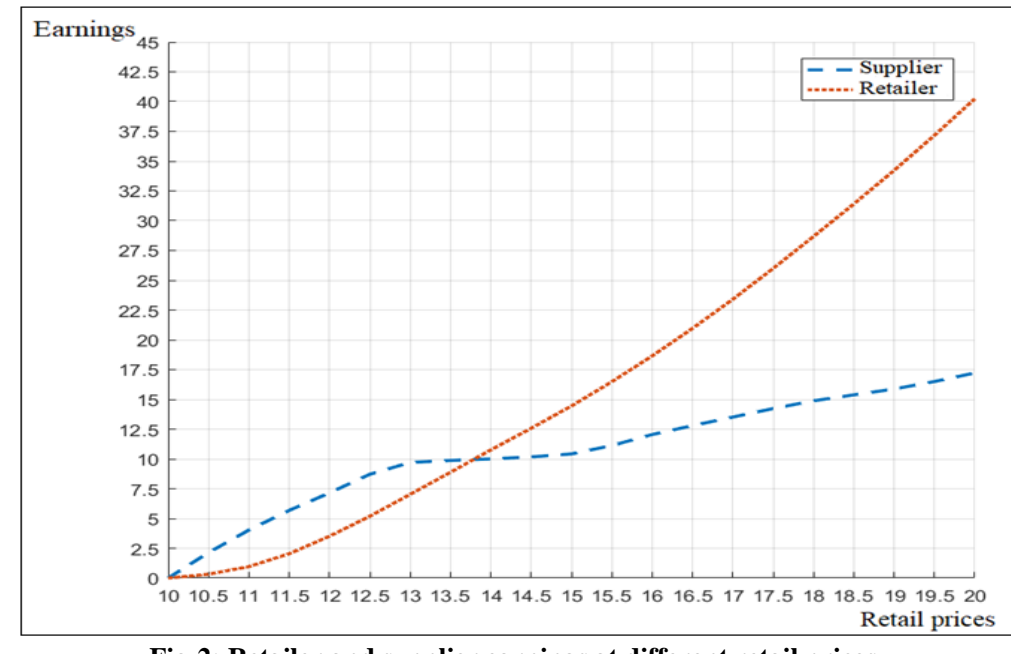

Fig-2: Retailer and supplier earnings at different retail prices

According to the chart, it can be seen that both retailer and supplier revenue increases as the retail price $p$ increases. For retailers, the retail price $p$ is closely linearly positively correlated with it, and the supplier's earnings are positively correlated with the retail price, but the trend is more moderate than the retailer. This is

Hypothesis 2, wholesale price of supplier:

$$
w \in[8,15]
$$

Solution Within a reasonable range, wholesale prices affect the profits of retailers and suppliers. The results are shown in the table below:

Table-3: Optimal Guarantee Ratios and Optimal Order ingress selling for retailers at different wholesale prices

\begin{tabular}{ccccc}
\hline$w$ & $\lambda$ & $\mathrm{Q}$ & $\pi_{r}$ & $\pi_{s}$ \\
\hline 8 & -- & 6.25 & 26.82 & 0.00 \\
9 & $27 \%$ & 7.55 & 20.42 & 7.55 \\
10 & $5 \%$ & 5.21 & 13.60 & 10.42 \\
11 & -- & 4.55 & 8.56 & 13.65 \\
12 & -- & 3.29 & 4.55 & 13.16 \\
13 & -- & 2.01 & 1.92 & 10.05 \\
14 & -- & 0.93 & 0.45 & 5.58 \\
15 & -- & 0.00 & 0.00 & 0.00 \\
\hline
\end{tabular}

Replace the data in the table and solve the retailer's earnings $\pi_{1}^{r}$ and $\pi_{2}^{s}$. The results are shown in the following figure: 


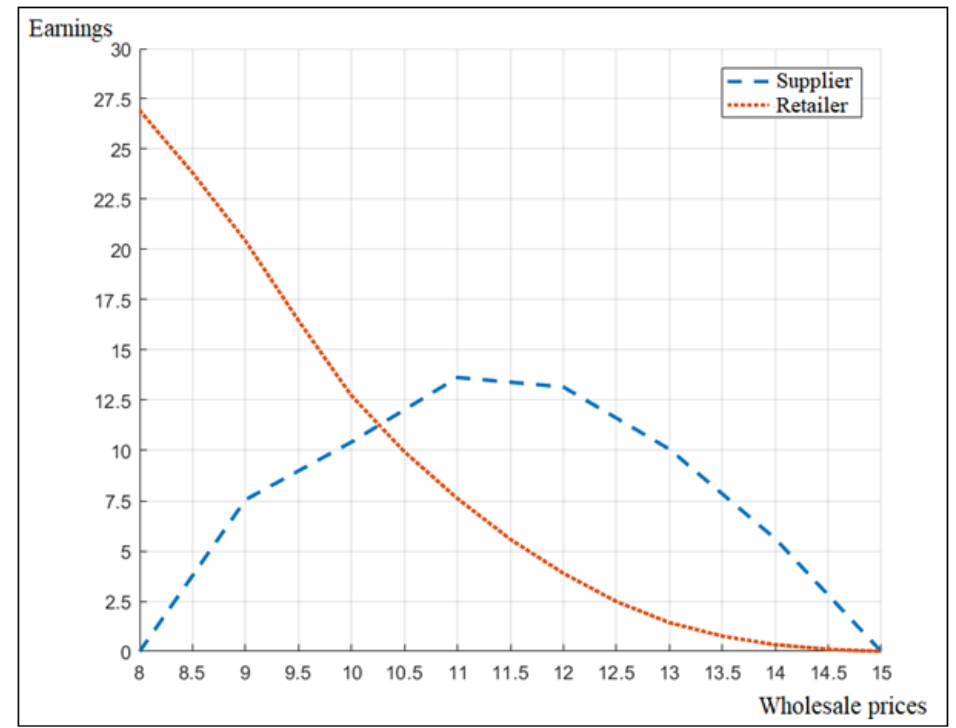

Fig-3: Retailer and supplier earnings at different wholesale prices

It can be seen that the effect of wholesale prices ${ }_{W}$ on retailers' earnings is broadly the opposite of the effect of retail prices $p$. For suppliers, the higher the wholesale price at $w<11$, the higher the supplier's revenue, and when wholesale prices increase to a certain extent, the retailer reduces the amount of ordering, resulting in a decline in supplier revenue. Therefore, it is very important for suppliers to set a reasonable wholesale price, and it will be counterproductive not to increase the wholesale price.

\section{Hypothesis 3, the residual value of the unit of goods:}

$$
v \epsilon[4,8]
$$

The solution is within a reasonable range of residual value of the goods, and the impact on the retailer and supplier revenue is shown in the following table:

Table-4: Optimal Guarantee Ratio and Optimal Order ingress for Retailers at Different Commodity Residual Values

\begin{tabular}{ccccc}
\hline$v$ & $\lambda$ & $\mathrm{Q}$ & $\pi_{r}$ & $\pi_{s}$ \\
\hline 4 & -- & 4.24 & 9.54 & 8.49 \\
4.5 & -- & 4.53 & 10.10 & 9.05 \\
5 & -- & 4.85 & 10.74 & 9.70 \\
5.5 & -- & 5.00 & 11.45 & 10.00 \\
6 & -- & 5.00 & 12.16 & 10.00 \\
6.5 & -- & 5.00 & 12.87 & 10.00 \\
7 & $5 \%$ & 5.21 & 13.60 & 10.42 \\
7.5 & $13 \%$ & 5.75 & 14.44 & 11.49 \\
8 & $23 \%$ & 6.41 & 15.44 & 12.82 \\
\hline
\end{tabular}

Replace the data in the table and solve the retailer's earnings $\pi_{1}^{r}$ and $\pi_{2}^{s}$. The results are shown in the following figure: 


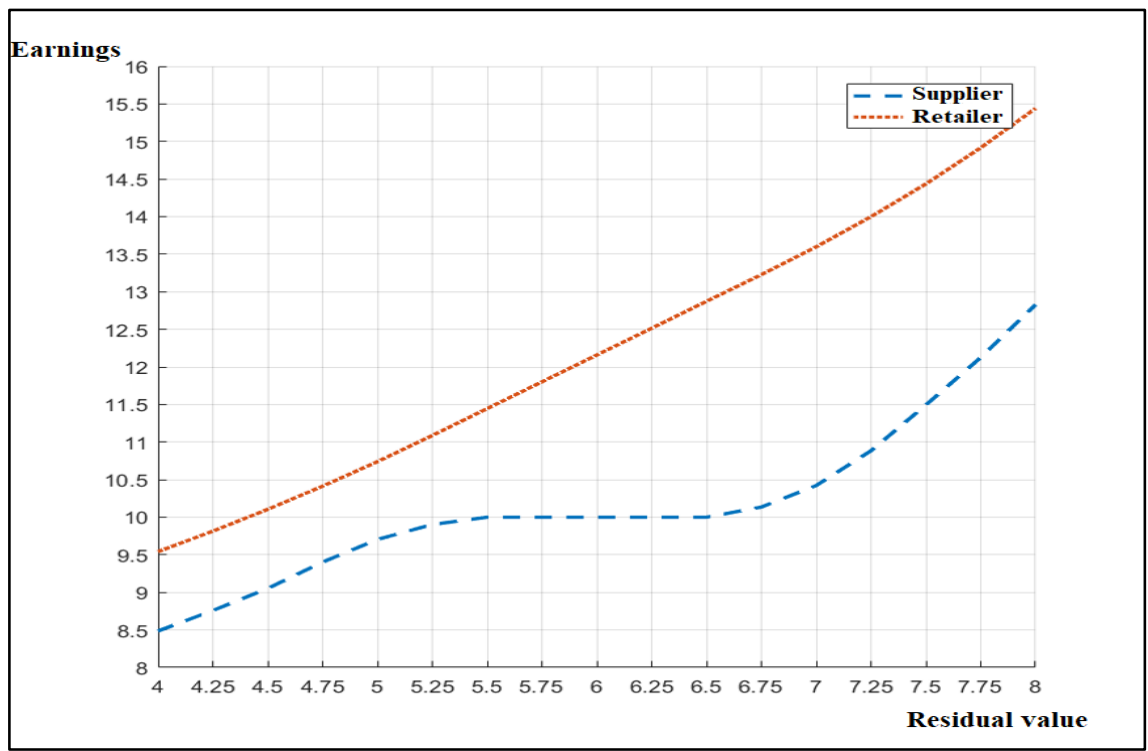

Fig-4: Retailer and supplier earnings at different commodity residuals $v$

For a retailer, the higher the residual value, the greater the benefit, so the increase in residual value will cause the retailer to increase the order volume and therefore the supplier's revenue increase.

\section{Hypothesis 4: Bank Loan Rate:}

$$
r=[0.05,0.2]
$$

Solve the impact of supplier $r$ earnings on retailers within a reasonable bank payment rate, as shown in the following table:

Table-5: Optimal Guarantee Ratios and Optimal Ordering S/ Retailers at Different Bank Rates

\begin{tabular}{ccccc}
\hline$r$ & $\lambda$ & $\mathrm{Q}$ & $\pi_{r}$ & $\pi_{s}$ \\
\hline 0.050 & $14 \%$ & 5.79 & 13.75 & 11.58 \\
0.055 & $13 \%$ & 5.69 & 13.71 & 11.38 \\
0.060 & $11 \%$ & 5.59 & 13.68 & 11.18 \\
0.065 & $9 \%$ & 5.49 & 13.65 & 10.98 \\
0.070 & $8 \%$ & 5.40 & 13.63 & 10.80 \\
0.075 & $6 \%$ & 5.30 & 13.61 & 10.60 \\
0.080 & $5 \%$ & 5.21 & 13.60 & 10.42 \\
0.085 & -- & 5.00 & 13.59 & 10.00 \\
0.090 & -- & 5.00 & 13.59 & 10.00 \\
\hline
\end{tabular}

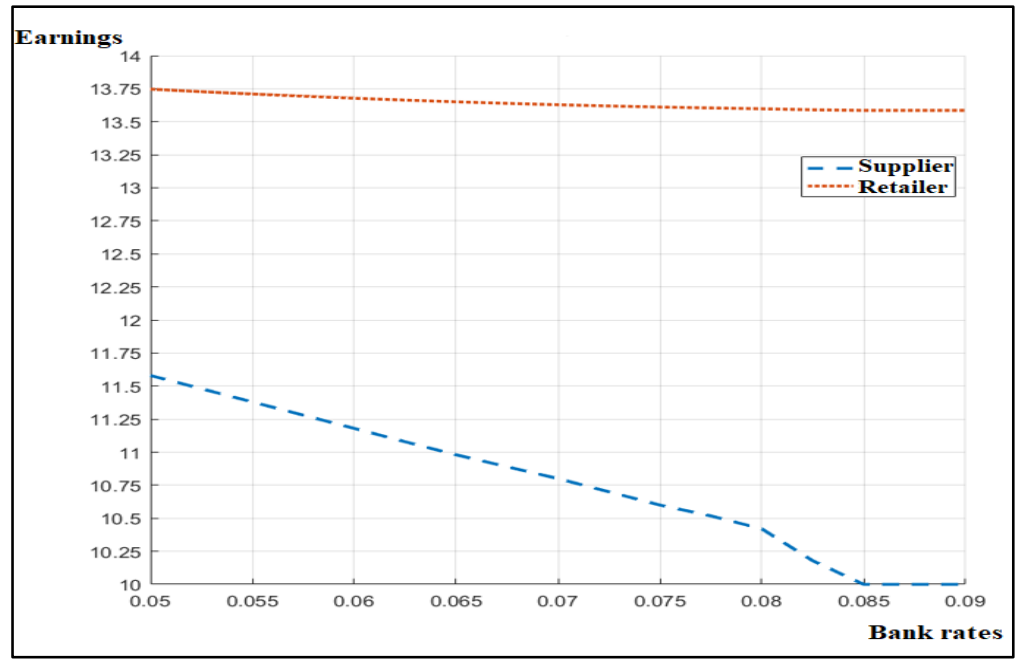

Fig-5: Retailer and supplier earnings at different bank rates $r$ 
As you can see, the maximum return smaller for suppliers and retailers decreases as interest rates $r$ increase, and after interest rates increase to a certain extent, both suppliers and retailers' earnings remain the same, i.e. retailers choose not to lend to banks. Therefore, from the point of view of supplier-centric enterprises, its earnings are affected by bank policy, negatively correlated with the bank's interest rate, and there is an optimal large guarantee ratio, which makes the supplier obtain the maximum profit.

At the same time, because the retailer needs to borrow, i.e.

$$
Q^{*}(\lambda, r)>L / w
$$
,the optimal order volume of

the retailer is affected by the bank rate and supplier guarantee ratio.

The study is based on the retailer's order volume $Q$, the supplier's guarantee ratio $\lambda$, and the bank's interest rate $r$ as decision variables. The optimal $Q$ value is a prerequisite for solving the benefits of the parties, and $Q^{*}$ is closely related to $\lambda$ and $r$. Traverse the value of $r$ within a reasonable range, solve the appropriate corresponding $\lambda$ value, and use this as a condition to obtain the optimal order $Q^{*}$. After the determination of the decision variables, for other parameters, such as $p, w, v$, to explore its impact on the benefits of the parties, from which the actual supply chain operation should pay attention to and clear matters.

\section{SUMMARY}

Suppliers act as core companies in the supply chain, providing guarantees to downstream retailers. With supplier credit guarantees, retailers can access external financing services that can encourage riskaverse banks to raise lending limits for moneyconstrained retailers. The results show that financing services can increase the order volume and profits of retailers, create new value for retailers, enhance the purchasing power of retailers, and improve the overall performance of the supply chain. Further research can assume that the relevant information of banks about the supply chain, especially the information on demand distribution is asymmetric, and the influence of information asymmetry on bank financing risk is reduced by designing supply chain financing contracts.

\section{REFERENCES}

1. Jing B, Seidmann A. Financing sourcing in a supply chain [J]. Decision Support System, 2014,
58(2): 15-20.

2. Qiang L, Jinying H. Supply chain contract design considering the supplier's asset structure and capital constraints [J]. Computers \& amp; Industrial Engineering, 2019,137.

3. Xu X, Birge J R. Equity valuation, production, and financial planning: A stochastic programming approach $[\mathrm{J}]$. Naval Research Logistics, 2006, 53(7): 641-655.

4. Hetrakul P, Cirillo C. A latent class choice based model system for railway optimal pricing and seat allocation [J]. Transportation Research Part E: Logistics and Transportation Review, 2014, 61: 68-83.

5. Hasani A, Zegordi SH, Nikbakhsh E. Robust closed-loop supply chain network design for perishable goods in agile manufacturing under uncertainty [J]. International Journal of Production Research, 2012, 50(16): 4649-4669.

6. Akbari A, Karimi B. A new robust optimization approach for integrated multi-echelon, multiproduct, multi-period supply chain network design under process uncertainty [J]. International Journal of Advanced Manufacturing Technology, 2015, 79.

7. Ramezani M, Bashiri M, Tavakkoli-Moghaddam R. A robust design for a closed-loop supply chain network under an uncertain environment $[\mathrm{J}]$. The International Journal of Advanced Manufacturing Technology, 2013: 1-19.

8. Vahdani B, Tavakkoli-Moghaddam R, Jolai F, Baboli A. Reliable design of a closed loop supply chain network under uncertainty: An interval fuzzy possibilistic chance-constrained model. Engineering Optimization. 2013 Jun 1;45(6):74565.

9. Pan F, Nagi R. Robust supply chain design under uncertain demand in agile manufacturing [J]. Computers \& Operations Research, 2010, 37(4): 668-683.

10. Mirzapour Al-E-Hashem SMJ, Malekly H, Aryanezhad MB. A multi-objective robust optimization model for multi-product multi-site aggregate production planning in a supply chain under uncertainty [J]. International Journal of Production Economics, 2011, 134(1): 28-42.

11. Wei C, Li Y, Cai X. Robust optimal policies of production and inventory with uncertain returns and demand $[\mathrm{J}]$. International Journal of Production Economics, 2011, 134(2): 357-367.

12. Li C, Liu S. A robust optimization approach to reduce the bullwhip effect of supply chains with vendor order placement lead time delays in an uncertain environment $[\mathrm{J}]$. Applied Mathematical Modelling, 2013, 37(3): 707-718. 